\title{
In situ absorption efficiency processes for the cultured mussel Mytilus galloprovincialis in Ría de Arousa (north-west Spain)
}

\author{
José M.F. Babarro*, María José Fernández-Reiriz and Uxío Labarta \\ CSIC, Instituto de Investigaciones Marinas, Eduardo Cabello 6, 36208 Vigo, Spain. \\ *Corresponding author, e-mail: jbabarro@iim.csic.es
}

\begin{abstract}
Mussel seed Mytilus galloprovincialis from two origins (rocky shore and collector ropes) was cultivated on a raft (submerged culture) in the Ría de Arousa (north-west Spain) from approximately $20 \mathrm{~mm}$ to $60 \mathrm{~mm}$ shell length. Absorption efficiencies (AEs) and absorption rates (ARs) of the individuals were recorded in situ throughout cultivation time from November to July (1995-1996). Absorption efficiencies varied according to a multiple model that highlighted the significant effect of quality of natural seston $(f$ as relative organic content), time of culture and origin of mussel seed. Initial AE values were 42 and $34 \%$ of the ingested organic material for collector ropes and rocky shore mussels $(P<0.01)$, respectively. These differences remained significant for the first two months of the culture with higher values for collector ropes mussels. A significant relationship AE vs quality of natural seston $(f)$ was observed according to an asymptotic equation: $\mathrm{AE}=0.82\left[1-\mathrm{e}^{-5.01(f-0.21)}\right]$ for both sources of seed $\left(r^{2}=0.90\right)$. Absorption rate $(\mathrm{mg}$ organic matter $\mathrm{g}^{-1} \mathrm{~h}^{-1}$ ) followed a seasonal pattern with low values in winter and higher values in spring-summer as a consequence of better nutritional quality of food resources. Nevertheless, exceptional peaks of organic material from sedimentary origin in January caused an increase of ingested/absorbed organic material despite its low nutritional quality. Differences in AR values between origins of mussel seed referred to the first month under culture, with higher values for collector ropes individuals. Original habitat of mussel seed usually employed in mussel culture in Galicia is responsible for long-lasting effects through physiological changes that the individuals from the rocky shore habitat presented when placed under raft-submerged culture.
\end{abstract}

\section{INTRODUCTION}

Mussel culture in Galician Rías involves a transplantation of mussel seed usually originating from two different habitats, intertidal rocky shore and subtidal collector ropes mussels, to submerged raft conditions (Pérez Camacho et al., 1995). Such transplantation imposes an abrupt change in feeding regime for those individuals adapted to an intertidal location, not only in terms of temporal availability of food but most likely also with differences in quantity and/or quality of food as a consequence of water currents, waves and stronger resuspension processes along the coastline. Variations in quantity and quality of food resources over short and/or long-term exposure periods may imply changes in recognized digestive parameters such as residence time of ingested matter in the intestine and digestive capacity (Bayne et al., 1989) which in turn may affect absorption efficiency processes (Labarta et al., 1997). A number of surveys have highlighted the extension of the effect that such transplantation of both mussel seeds may cause on their physiological behaviour and eventually growth potential when cultured on a raft (Perez Camacho et al., 1995; Labarta et al., 1997; Babarro et al., 2000a,b,c). Fluctuation of environmental parameters generally causes physiological compensations of the individuals to a given habitat in order to optimize their energy gains. Therefore, a physiological adaptation response of each source of mussel seed to its habitat has been assumed, which in turn might have caused both types of seed to be in a different physiological state at the onset of raft culture (Babarro et al., 2000a). The latter assumption has been investigated taking into consideration different physiological parameters like feeding (Babarro et al., 2000b) and energy-consuming activities (Babarro et al., 2000c). However, the main compensatory response of bivalve filter feeders to variable diets for the optimization of net energy gain has been identified to be the regulation of digestive processes (Bayne et al., 1989), which in turn would define absorption rates of organic seston available. In this study the influence that the original habitat of both sources of seed commonly used on mussel culture in Galician Rías may cause on aspects related to absorption efficiency processes has been studied.

\section{MATERIALS AND METHODS}

\section{Individuals and experimental design}

Mussel seed of Mytilus galloprovincialis of approximately $20 \mathrm{~mm}$ in length was gathered from the rocky shore and collector ropes on a raft, both in the mid-outer area of the Ría de Arousa (Galicia, north-west Spain). Both groups of mussels were detached from pre-cleaned intertidal and collector areas and subsequently allowed to 
re-attach to cultivation ropes on the raft using the standard procedure of the mussel culture in Spain (linen net which degraded itself after some days in seawater). Both types of seed from the same year class came from spawning period in the previous spring-summer and the sampling locations are $2 \mathrm{~km}$ away from each other. Experimental culture was carried out in a raft usually employed for the commercial culture in Ría de Arousa $\left(500 \mathrm{~m}^{2}\right)$, began in winter 1995 (November) and continued until July 1996 (226 days) covering the first stage of mussel culture from seeding $(20 \mathrm{~mm})$ to thinning out $(50-60 \mathrm{~mm})$. Initial average lengths $( \pm \mathrm{SD})$ were $22.5 \pm 1.5$ and $19.0 \pm 1.96 \mathrm{~mm}$ for the seed from collector ropes and rocky shore, respectively. Average total dry weights (DW) and soft tissue DW were $0.36 \pm 0.06$ and $0.27 \pm 0.06 \mathrm{~g}$ total $\mathrm{DW} /$ individual and, $0.040 \pm 0.005$ and $0.033 \pm 0.006 \mathrm{~g}$ soft tissue $\mathrm{DW} /$ individual, for both mussels from collector ropes and rocky shore, respectively. Details of the experimental design in terms of number of specimens used, water flow etc. were reported specifically in a previous article (Babarro et al., 2000b) referred to clearance and/or ingestion rate measurements under natural conditions on the raft.

\section{Measurements}

Natural seston was characterized as total particulate matter (TPM mgl ${ }^{-1}$ ), particulate organic matter (POM $\mathrm{mgl}^{-1}$, particulate inorganic matter (PIM $\left.\mathrm{mgl}^{-1}\right)$, particulate volume (Vol mm $\mathrm{m}^{3}$ ) and chlorophyll- $a$ (chl- $a$ $\left.\mu \mathrm{gl}^{-1}\right)$ as well as temperature $\left(\mathrm{T}^{\circ} \mathrm{C}\right)$ and salinity ( $\left.\mathrm{S} \mathrm{psu}\right)$ values of the water column. Seston quality was expressed as $f(\mathrm{POM} / \mathrm{TPM}), \mathrm{Q}_{2}(\mathrm{POM} / \mathrm{Vol})$ and the chl- $a / \mathrm{POM}$ index. Variability of these environmental and/or nutritional parameters over the cultivation period is shown in Table 1. Methodological aspects and descriptive variability of the latter parameters were reported in a previous paper (Babarro et al., 2000a). Samples of natural seston and faeces produced over a period of $4 \mathrm{~h}$ were collected twice and, filtered on Whatman $\mathrm{GF} / \mathrm{C}$ filters and processed for TPM and POM computation. Absorption efficiency (AE) was then quantified, according to Conover (1966) as follows:

$\mathrm{AE}=(\mathrm{F}-\mathrm{E}) /(1-\mathrm{E}) \cdot \mathrm{F}$, where $\mathrm{F}$ and $\mathrm{E}$ are the organic content (by weight) of food and faeces, respectively.

Absorption rate (AR, mg POM g ${ }^{-1} h^{-1}$ ) was calculated as the product of $\mathrm{AE}$ and organic ingestion rate (OIR).

Table 1. Characteristics of the natural seston (means $\pm S D$ ).

\begin{tabular}{|c|c|c|c|c|c|c|c|c|c|c|}
\hline Date & $\begin{array}{c}\text { TPM } \\
\left(\mathrm{mg} \mathrm{l}^{-1}\right)\end{array}$ & $\begin{array}{c}\text { POM } \\
\left(\mathrm{mg} \mathrm{l}^{-1}\right)\end{array}$ & $\begin{array}{c}\text { PIM } \\
\left(\mathrm{mg} \mathrm{l}^{-1}\right)\end{array}$ & $\begin{array}{c}\text { Vol } \\
\left(\mathrm{mm}^{3} \mathrm{l}^{-1}\right)\end{array}$ & $\begin{array}{c}\mathrm{T} \\
\left({ }^{\circ} \mathrm{C}\right)\end{array}$ & $\begin{array}{c}\text { S } \\
(\mathrm{psu})\end{array}$ & $\begin{array}{l}\text { Chl- } a \\
\mu \mathrm{g} \mathrm{l} \mathrm{l}^{-1}\end{array}$ & $\begin{array}{c}f \\
(\mathrm{POM} / \\
\text { TPM })\end{array}$ & $\begin{array}{c}\mathrm{Q}_{2} \\
\mathrm{POM} / \\
\mathrm{Vol})\end{array}$ & $\begin{array}{l}\text { Chl- } a \\
\text { / POM }\end{array}$ \\
\hline $27 / 11 / 95$ & $0.68 \pm 0.18$ & $0.37 \pm 0.11$ & 0.30 & $0.57 \pm 0.29$ & $15.7 \pm 0.7$ & $32.8 \pm 1.9$ & $0.75 \pm 0.18$ & 0.54 & 0.65 & 2.02 \\
\hline $05 / 12 / 95$ & $49 \pm 0.15$ & $0.29 \pm 0.04$ & 0.20 & $0.39 \pm 0.21$ & $15.4 \pm 1.1$ & $31.3 \pm 4.7$ & $0.36 \pm 0.27$ & 0.59 & 0.75 & 1.24 \\
\hline $13 / 12 / 95$ & $0.83 \pm 0.11$ & $0.31 \pm 0.03$ & 0.52 & $0.52 \pm 0.09$ & $15.6 \pm 0.4$ & $35.2 \pm 0.5$ & $0.48 \pm 0.15$ & 0.37 & 0.60 & 1.55 \\
\hline 20/12/95 & $0.74 \pm 0.21$ & $0.37 \pm 0.08$ & 0.36 & $0.45 \pm 0.08$ & $13.7 \pm 0.4$ & $34.8 \pm 0.4$ & $0.61 \pm 0.15$ & 0.50 & 0.82 & 1.65 \\
\hline 03/01/96 & $2.56 \pm 0.68$ & $1.00 \pm 0.27$ & 1.56 & $1.29 \pm 0.09$ & $14.3 \pm 0.3$ & $30.1 \pm 2.9$ & $0.36 \pm 0.36$ & 0.39 & 0.78 & 0.36 \\
\hline $17 / 01 / 96$ & $0.79 \pm 0.06$ & $0.46 \pm 0.02$ & 0.33 & $0.51 \pm 0.08$ & $13.9 \pm 0.6$ & $28.0 \pm 4.8$ & $0.29 \pm 0.28$ & 0.58 & 0.90 & 0.63 \\
\hline $31 / 01 / 96$ & $0.55 \pm 0.07$ & $0.28 \pm 0.03$ & 0.27 & $0.29 \pm 0.05$ & $13.2 \pm 0.3$ & $30.1 \pm 1.4$ & $0.64 \pm 0.27$ & 0.51 & 0.95 & 2.29 \\
\hline $15 / 02 / 96$ & $1.34 \pm 0.20$ & $0.39 \pm 0.06$ & 0.95 & $0.71 \pm 0.06$ & $13.9 \pm 0.6$ & $31.1 \pm 2.2$ & $1.43 \pm 0.35$ & 0.29 & 0.54 & 3.67 \\
\hline $28 / 02 / 96$ & $1.31 \pm 0.11$ & $0.57 \pm 0.08$ & 0.74 & $1.07 \pm 0.14$ & $12.9 \pm 0.3$ & $34.1 \pm 1.4$ & $1.16 \pm 0.18$ & 0.43 & 0.53 & 2.04 \\
\hline $13 / 03 / 96$ & $0.88 \pm 0.22$ & $0.46 \pm 0.10$ & 0.42 & $0.90 \pm 0.29$ & $13.1 \pm 0.1$ & $34.9 \pm 0.4$ & $1.19 \pm 0.37$ & 0.52 & 0.51 & 2.59 \\
\hline $27 / 03 / 96$ & $0.96 \pm 0.17$ & $0.52 \pm 0.08$ & 0.4 & $1.26 \pm 0.26$ & $13.8 \pm 0.2$ & $33.1 \pm 0.4$ & $1.71 \pm 0.28$ & 0. & 0. & 3.29 \\
\hline $10 / 04 / 96$ & $1.48 \pm 0.12$ & $0.64 \pm 0.04$ & 0.84 & $1.66 \pm 0.15$ & $14.4 \pm 0.5$ & $32.5 \pm 2.7$ & $1.96 \pm 1.60$ & 0.43 & 0.39 & 3.06 \\
\hline $24 / 04 / 96$ & $0.74 \pm 0.09$ & $0.39 \pm 0.02$ & 0.35 & $0.65 \pm 0.15$ & $15.0 \pm 0.6$ & $33.7 \pm 1.7$ & $1.59 \pm 0.35$ & 0.53 & 0.60 & 4.08 \\
\hline $05 / 06 / 96$ & $0.62 \pm 0.09$ & $0.29 \pm 0.04$ & 0.33 & $0.76 \pm 0.10$ & $15.0 \pm 1.2$ & $35.0 \pm 0.9$ & $1.11 \pm 0.59$ & 0.47 & 0.38 & 3.83 \\
\hline $03 / 07 / 96$ & $0.72 \pm 0.13$ & $0.43 \pm 0.08$ & 0.29 & $0.64 \pm 0.16$ & $14.3 \pm 0.7$ & $35.6 \pm 0.2$ & $1.03 \pm 0.30$ & 0.60 & 0.67 & 2.39 \\
\hline
\end{tabular}

TPM, total particulate matter; POM, particulate organic matter; PIM, particulate inorganic matter; Vol, total particulate volume; T, temperature; S, salinity; Chl- $a$, chlorophyll- $a ; f$, relative organic content (by weight). Q 2 , relative organic content (by volume); Chl- $a$ / POM, chlorophyll- $a$ content (by total organic weight).

Table 2. Stepwise multiple regression analysis of absorption effciency values (arcsine transformed variable) for individuals of Mytilus galloprovincialis with quality of natural seston (inverse, 1/f), logarithm of time (log time) and origin of mussel seed for data set of the whole experimental culture.

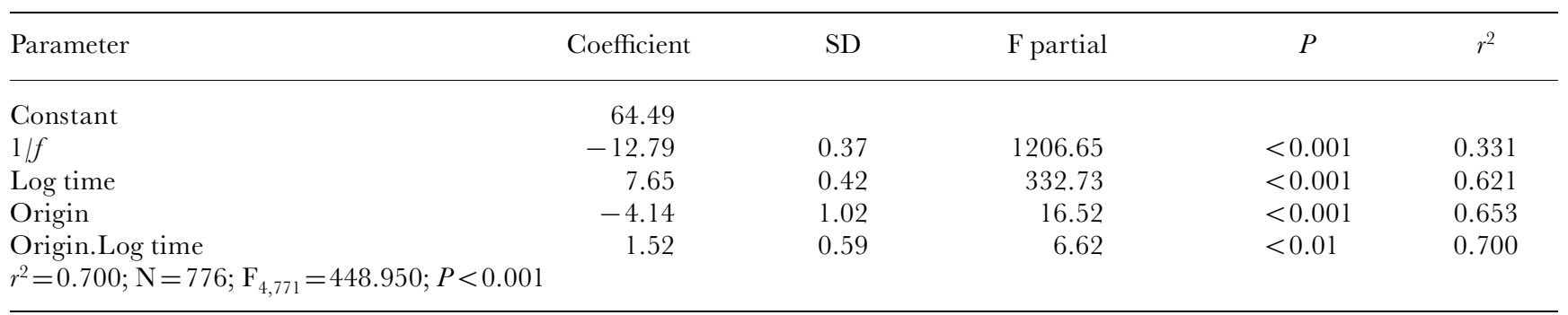




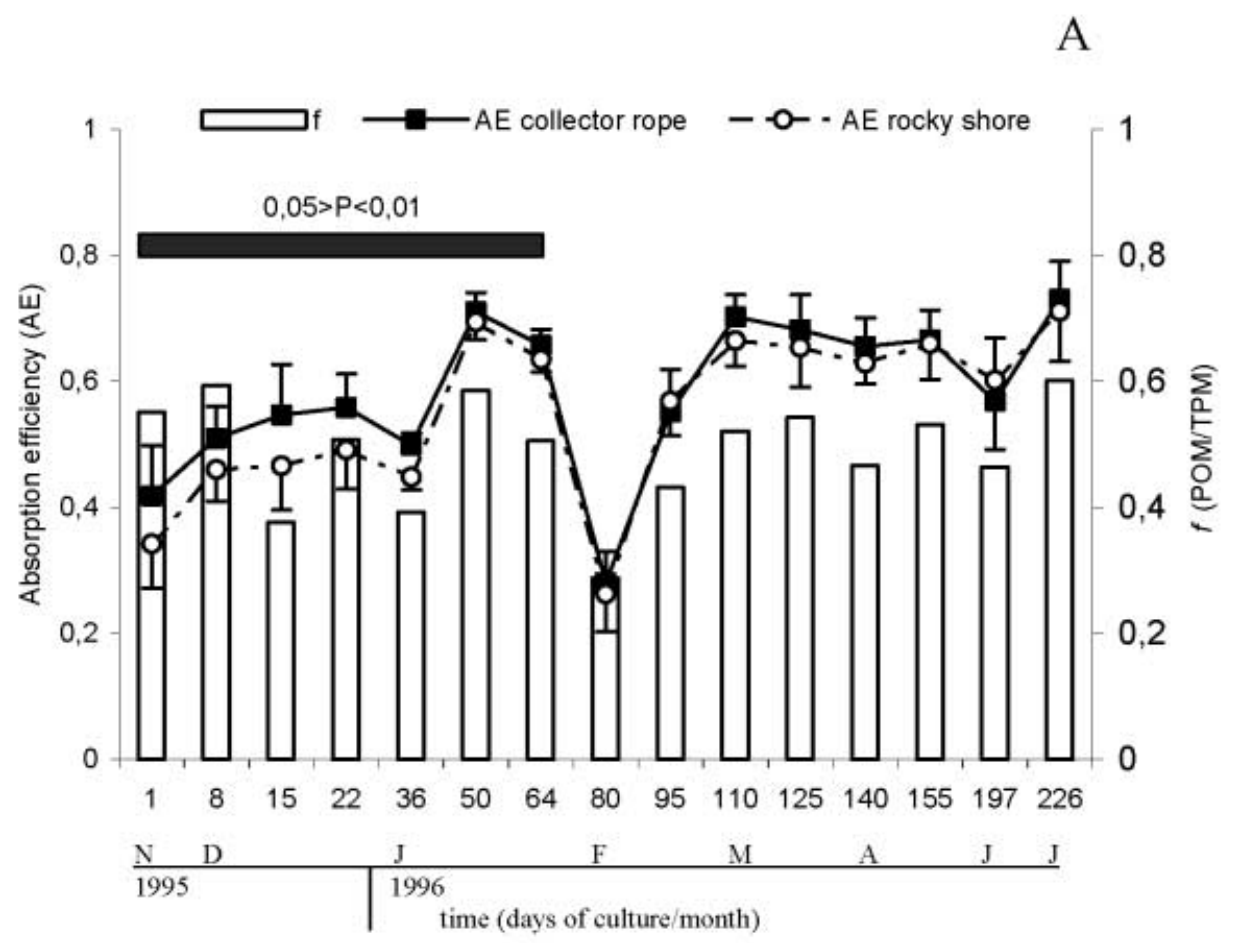

B

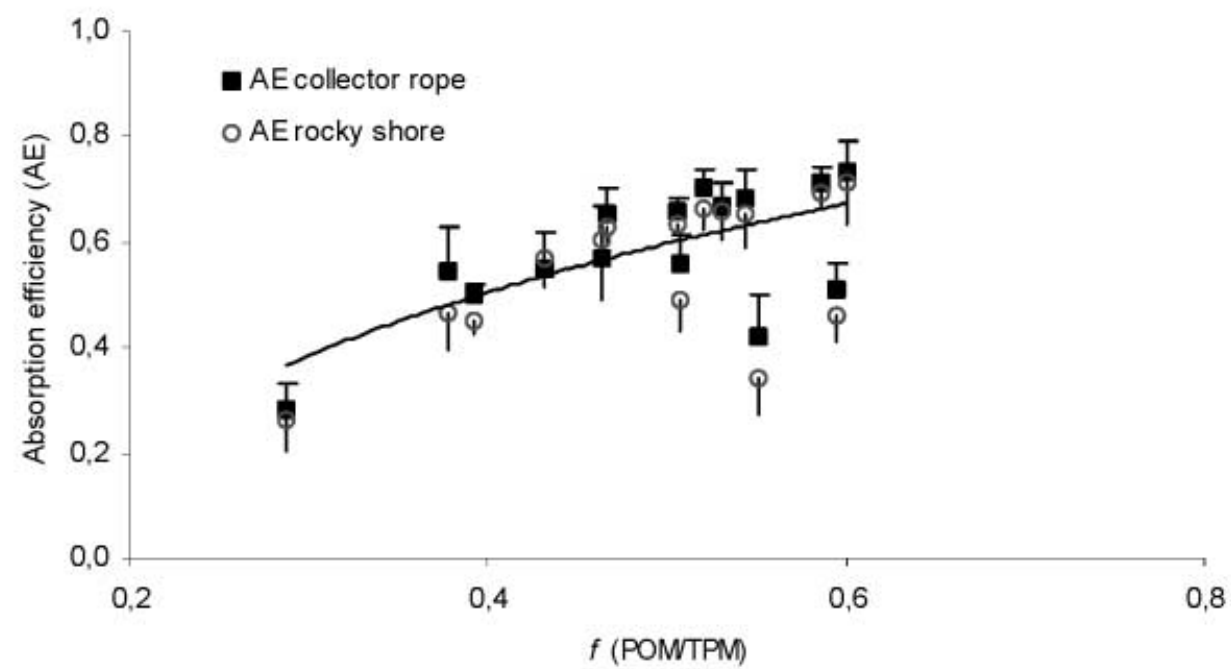

Figure 1. (A) Fluctuation of absorption efficiency values (mean $\pm \mathrm{SD} ; \mathrm{N}=32$ ) for collector ropes (subtidal) and rocky shore (intertidal) mussels throughout cultivation time. Seston quality $(f, \mathrm{POM} / \mathrm{TPM})$ variability is also shown; (B) relationship absorption efficiency vs quality of natural seston $(f, \mathrm{POM} / \mathrm{TPM})$ for both mussels groups (collector rope and rocky shore individuals). A common hyperbolic equation for both groups of mussels is presented.

For OIR values and standardization method see Babarro et al. (2000b). One gram of soft tissue dry weight was used for standardizing physiological responses according to the formula:

$\mathrm{Y}_{\mathrm{s}}=\mathrm{Y}_{\mathrm{e}}\left(\mathrm{DW}_{\mathrm{s}} / \mathrm{DW}_{\mathrm{e}}\right)^{\mathrm{b}}$

where $\mathrm{Y}_{\mathrm{s}}$ and $\mathrm{Y}_{\mathrm{e}}$ are the standardized and non standardized physiological rate, respectively; $\mathrm{DW}_{\mathrm{s}}$ and $\mathrm{DW}_{\mathrm{e}}$ are the standardized weight of the animal $(1 \mathrm{~g})$ and the observed experimental weight of the individuals, respectively; $\mathrm{b}$ is the power that scales physiological rate with weight of mussels $(b=0.599$, Pérez Camacho et al., 2000).

\section{Data analysis}

Standard analysis of variance (ANOVA) was used to compare means for both physiological parameters (AE and AR). Multiple analysis (stepwise regression) was used to determine the effect of environmental parameters and source of mussel seed on AE variability. Mussel origin 


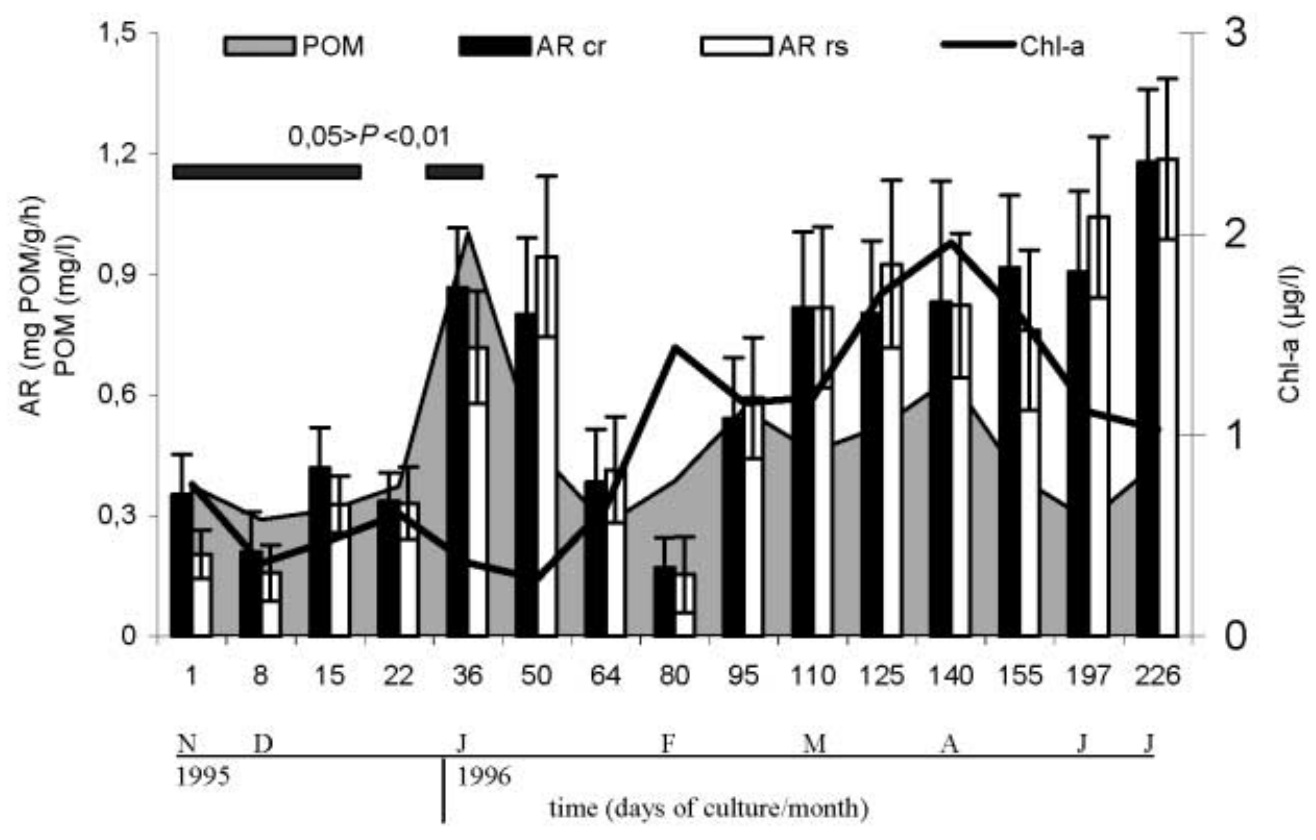

Figure 2. Absorption rate values ( $\mathrm{AR}, \mathrm{mg} \mathrm{POM} \mathrm{g} \mathrm{g}^{-1} \mathrm{~h}^{-1}$ mean $\pm \mathrm{SD} ; \mathrm{N}=32$ ) for both groups of mussels (cr, collector ropes; rs, rocky shore) throughout cultivation time. Variability of particulate organic material (POM, mg $\mathrm{l}^{-1}$ ) and chlorophyll- $a$ values $\left(\mu \mathrm{gl}^{-1}\right)$ is also shown.

represented a qualitative variable with values of 0 and 1 for collector ropes and rocky shore individuals, respectively. A significant relationship $\mathrm{AE}$ vs $f$ (quality of natural seston) was established according to a theoretical hyperbolic curve:

$\mathrm{Y}=\mathrm{a}\left[1-\mathrm{e}^{\mathrm{b} .(\mathrm{f}-\mathrm{c})}\right]$

where a, b and c represent parameters describing, respectively, the maximum value for $\mathrm{AE}$, the rate at which maximum $\mathrm{AE}$ is approached with increase in quality and the value for quality at which $\mathrm{AE}$ is 0 .

\section{RESULTS}

\section{Absorption efficiency (AE)}

Absorption efficiency values for both groups of mussels (collector ropes and rocky shore) throughout the cultivation period are shown in Figure 1A. Fluctuation of natural seston quality as relative organic content $(f)$ is also presented. $f$ varied between 0.3 and 0.6 , showing a greater oscillation in winter and narrower range around 0.5 during spring, close to values usually observed in Ría de Arousa. Absorption efficiency also varied within a relatively wide range of values throughout winter months (from the lowest values of $0.26-0.28$ in February to maximums of $0.71-0.69$ in January), whereas a more homogeneous range was observed in spring-summer for both sources of mussel seed (0.55-0.73; Figure 1A). A multiple analysis carried out on AE variability highlighted the effect of quality of natural seston, time of culture and origin of mussel seed, in order of importance, as significant factors affecting AE variability $(P<0.001)$ as well as the interaction term origin.log time $(P<0.01)$, the model explaining up to $70 \%$ of $\mathrm{AE}$ variability (Table 2 ).
The effect of the origin of mussel seed on AE variability was related to the fact that mussels from the collector ropes showed significantly higher AE as compared to those from the rocky shore at the onset of the culture (see Figure 1A). The significant influence of the interaction term origin.log time (see Table 2) would be an illustration that such differences by origin factor depend on culture time, being significant during the first two months of the culture. At the onset of the culture, mussels from the collector ropes showed AE values 22\% higher than those from the rocky shore (41.8 vs $34.2 \%$, respectively), which can be interpreted as values that both groups of mussels might present at their original habitats. Differences in AE values did last until February, always collector rope mussels presenting higher values than those from the rocky shore, the latter differences disappearing from the end of February onwards (Figure 1A).

Absorption efficiency vs quality of seston $(f)$ relationship could be fitted according to a theoretical hyperbolic curve for both types of mussels (see Materials and Methods; Figure 1B). Analysis of covariance performed on equations of both mussel groups under study showed no differences between slopes $(\mathrm{t}=0.012 ; \mathrm{df}=26 ; P>0.05)$ or intercepts $(\mathrm{t}=0.844 ; \mathrm{df}=27 ; P>0.05)$. Therefore, both groups of mussels were fitted to similar curves and an integrated single equation is shown in Figure $1 \mathrm{~B}$ for both groups together as follows:

$$
\begin{gathered}
\mathrm{AE}=0.82 \pm 0.12\left[1-\mathrm{e}^{-5.01 \pm 1.43(f-0.21 \pm 0.04)}\right] \\
\mathrm{N}=30 ; r^{2}=0.90 ; \quad P<0.001
\end{gathered}
$$

\section{Absorption rate (AR)}

Absorption rate values $\left(\mathrm{mg}\right.$ POM $\mathrm{h}^{-1}$ ) for a mussel of $1 \mathrm{~g}$ dry weight from both origins (collector ropes vs rocky 
shore) are shown in Figure 2. Seasonality patterns could be drawn for absorption rates of both groups of mussels between low values in the winter months $(0.15-0.42 \mathrm{mg}$ POM $\mathrm{g}^{-1} \mathrm{~h}^{-1}$ ) and higher values during the springsummer season (0.81-1.20 mg POM g ${ }^{-1} \mathrm{~h}^{-1}$; Figure 2). A similar profile was observed for chlorophyll- $a$ fluctuation during the culture from lower values in winter (0.3$\left.0.7 \mu \mathrm{gl}^{-1}\right)$ to higher range of values in spring-summer $\left(1.1-2.0 \mu \mathrm{g} \mathrm{l}^{-1}\right.$; Figure 2). Nevertheless, an exception to the latter seasonal pattern of AR could be observed in January, with high organic loads most probably due to detritical sedimentary material re-suspended in the water column, which caused an increase of ingestion/absorption rates (see Discussion). In the latter case, although chlorophyll- $a$ values are low, exceptional peaks of organic particulate matter did cause high values of absorption rates (0.8-0.9 mg POM $\mathrm{g}^{-1} \mathrm{~h}^{-1}$ ) comparable to those values observed during spring-summer (see Figure 2). Differences in AR between both groups of mussels referred to the first month under culture (Figure 2) with higher values for collector ropes mussels as consequence of differences reported in AE (present study) and organic ingestion rate (see Discussion).

\section{DISGUSSION}

In situ surveys focusing on absorption processes, as the main energy gain parameter, that mussels may carry out under natural conditions on the submerged Galician raft culture are rather scarce. The present results highlighted the effect that mussel seed coming from different original habitats may cause on absorption processes of cultured mussels when compared to other physiological parameters previously studied like feeding and metabolic activities (see Babarro et al., 2000b and c, respectively). Absorption efficiency is, therefore, the physiological parameter with more persistent differences between origins of mussel seed under study, for up to two months of cultivation time (Figure 1A). The latter fact observed for cultured mussels in nature corroborates previous results in which both groups of mussels (adult age) were maintained under laboratory conditions (Labarta et al., 1997). According to these authors, differences in scope for growth values between both groups of mussels at laboratory were mainly accounted for by persistence of differences in $\mathrm{AE}$ values after, at least, two weeks.

We might assume a long-lasting environmental effect through physiological adaptations in terms of AE patterns in a different early life history of both groups of mussels characterized by strong differences in feeding regime and other restricted factors that defined intertidal environment as compared to submerged conditions. The fact that experimental culture began in winter characterized by lower nutritional quality of natural food available might have also affected plasticity of digestive system in terms of time necessary to completely adapt their responses (rocky shore individuals) to new and better environmental and/ or nutritional conditions on the raft. Nevertheless, it is remarkable the catch-up process that rocky shore individuals performed on $\mathrm{AE}$ responses as compared to those from collector ropes after the first months of culture (Figure 1A). On this catch-up process plasticity of enzymatic digestive activity might have played a significant role in response to abrupt changes in food regimes as a transplant of rocky shore individuals to raft culture does suggest. For the specific case of subtidal Mytilus galloprovincialis transplanted to an intertidal regime for a month, Fernández Reiriz et al. (2001b) have observed a significant reduction of enzymatic activities as a consequence of changing trophic conditions. Moreover, a crossover transplant between intertidal and subtidal individuals of Mytilus chilensis for a week caused an increase of enzymatic resources when intertidal specimens were placed at submerged conditions (Fernández Reiriz et al., 2001a).

Differences in AR values by origin of mussel seed referred to the first month under culture (Figure 2) as a consequence of values reported in $\mathrm{AE}$ (up to 64 days; present study) and only initial differences in OIRs (Babarro et al., 2000b). Absorption rate profiles showed a seasonal variation for both groups of mussels (Figure 2). The latter pattern was due to fluctuation of environmental and/or nutritional parameters (mainly quality of seston, chlorophyll- $a$ and temperature) that affected significantly clearance and OIRs (see Babarro et al., $2000 \mathrm{~b})$. However, individuals took advantage from the presence of organic detritus material in winter due to storms and unstable environmental conditions in January (Table 1) that caused an increase of ingestion and/or absorption rates despite a drop of both $\mathrm{AE}$, as a consequence of lower quality of food (see Figure 1A), and clearance rates due to relatively high seston loads (see Babarro et al., 2000b). Although POM values did not show a clear seasonal fluctuation between winter and spring-summer, chlorophyll- $a$ levels would indicate a higher nutritional quality of food in this period associated to higher ingestion/absorption rates observed (see Figure 2).

Summarizing, it can be said that in situ absorption efficiency values of cultured mussels in Ría de Arousa fluctuated according to quality of seston $(f)$ as main environmental parameter. The influence of both origin of mussel seed and cultivation time did point out the plasticity of individuals in terms of $\mathrm{AE}$ processes when subjected to raft culture and might suggest digestive adaptation processes as most likely explanation for a long-lasting effect of original habitat mediated through physiological changes in early life history as well as catchup processes carried out by rocky shore individuals once placed under raft culture. Most likely, plasticity of the digestive system processes requires longer time for those individuals from the rocky shore to fully adapt to culture submerged conditions on the raft as differences regarding their intertidal original habitat in terms of feeding regime (both quantity and quality of available food) and air exposure (cease of feeding activity) are notorious.

We are grateful to Lourdes Nieto, Beatriz González and Sonia Villar for technical assistance. The authors are also indebted to the crew of 'José María Navaz' from the Instituto Español de Oceanografía. We also thank Juan Maneiro from Centro de Control da Calidade do Medio Mariño da Consellería de Pesca, Marisqueo e Acuicultura (Xunta de Galicia) for chlorophyll- $a$, temperature and salinity determinations. This study was supported by Project CICYT MAR97-0592. J.M.F.B. was funded by a grant from Excma., Diputación de Pontevedra. 
1064 J.M.F. Babarro et al. In situ absorption efficiency values of Mytilus galloprovincialis

\section{REFERENCES}

Babarro, J.M.F., Fernández Reiriz, M.J. \& Labarta, U., 2000a. Growth of seed mussel (Mytilus galloprovincialis Lmk): effects of environmental parameters and seed origin. Journal of Shellfish Research, 19, 187-193.

Babarro, J.M.F., Fernández Reiriz, M.J. \& Labarta, U., 2000b. Feeding behaviour of seed mussel Mytilus galloprovincialis: environmental parameters and seed origin. Fournal of Shellfish Research, 19, 195-201.

Babarro, J.M.F., Fernández Reiriz, M.J. \& Labarta, U., 2000c. Metabolism of the mussel Mytilus galloprovincialis from two origins in the Ría de Arousa (north-west Spain). Fournal of the Marine Biological Association of the United Kingdom, 80, 865-872.

Bayne, B.L., Hawkins, A.J.S., Navarro, E. \& Iglesias, J.I.P., 1989. Effects of seston concentration of feeding, digestion and growth in the mussel Mytilus edulis. Marine Ecology Progress Series, 55, 47-59.

Conover, R.J., 1966. Assimilation of organic matter by zooplankton. Limnology and Oceanography, 11, 338-354.

Fernández Reiriz, M.J., Labarta, U., Navarro, J.M. \& Velasco, A., 2001a. Enzymatic digestive activity in Mytilus chilensis (Hupé 1854) in response to food regimes and past feeding history. Fournal of Comparative Physiology, 171B, 449-456.
Fernández Reiriz, M.J., Labarta, U. \& Babarro, J.M.F., 2001b. Actividades enzimáticas del estilo cristalino de Mytilus galloprovincialis (L.). Influencia del origen y del ciclo de mareas. Monografias del Instituto Canario de Ciencias Marinas, 4, 21-26. [In Spanish.]

Labarta, U., Fernández Reiriz, M.J. \& Babarro J.M.F., 1997. Differences in physiological energetics between intertidal and raft cultivated mussels Mytilus galloprovincialis. Marine Ecology Progress Series, 152, 167-173.

Pérez Camacho, A., Labarta, U. \& Beiras, R., 1995. Growth of mussels (Mytilus edulis galloprovincialis) on cultivation rafts: influence of seed source, cultivation site and phytoplankton availability. Aquaculture, 138, 349-362.

Pérez Camacho, A., Labarta, U. \& Navarro, E., 2000. Energy balance of mussels Mytilus galloprovincialis: the effect of length and age. Marine Ecology Progress Series, 199, 149-158.

Submitted 24 October 2002. Accepted 21 July 2003. 